\title{
Evaluation of the Effect of Time Change in Cognitive Function in Volunteers in Tehran
}

\author{
Marjan Erfani ${ }^{1,2}$, Hedayat Sahraei ${ }^{3}$, Zahra Bahari ${ }^{4}$, Gholam Hossein Meftahi ${ }^{3}$, Boshra Hatef ${ }^{3}$, Alireza \\ Mohammadi $^{3} \&$ Seyed Hossein Hosseini ${ }^{3}$ \\ ${ }^{1}$ Biotechnology Research Center, Tabriz University of Medical Sciences, Tabriz, Iran \\ ${ }^{2}$ Higher Academic Education Institute of Rab-Rashid, Tabriz, Iran \\ ${ }^{3}$ Neuroscience Research Center, Baqiyatallah University of Medical Sciences, Tehran, Iran \\ ${ }^{4}$ Department of Physiology and Biophysics, Faculty of Medicine, Baqiyatallah University of Medical Sciences, \\ Tehran, Iran \\ Correspondence: Gholam Hossein Meftahi, Neuroscience Research Center, Baqiyatallah University of Medical \\ Sciences, Tehran, P. O. Box: 19395-6558, Iran. Tel/Fax: 98-21-2612-7257. E-mail: hossein.meftahi@bmsu.ac.ir; \\ meftahi208@yahoo.com
}

Received: April 18, 2016 Accepted: June 21, 2016 Online Published: June 30, 2016

doi:10.5539/gjhs.v9n2p119 URL: http://dx.doi.org/10.5539/gjhs.v9n2p119

\begin{abstract}
Background: Time change (which can lead to sleep duration decrements) can lead to brain dysfunction if repeated. In the present study, cognitive functions of the volunteers were evaluated before and after the time changes in Tehran.
\end{abstract}

Methods: Eleven, voluntary healthy persons (21 2 year old) were evaluated for their cognitive functions including sustain attention, reaction time, and mental fatigue twenty-one days before the time changes and thirty-eight days after time change using PASAT software. In addition, plasma cortisol level was measured before and after the time changes.

Results: After the time changes salivary cortisol concentration increase, but general mental health was decreased. Sustain attention was shortened after time change which was significantly different compared with before the time changes. Reaction time was increased after the time changes in comparison with the before the time changes, but was not statistically significant. In addition, mental fatigue was increased after the time changes.

Conclusion: It seems that time change may reduce brain cognitive functions which are manifested by general mental health, sustain attention reduction, reaction time as well as mental fatigue.

Keywords: PASAT software, mental fatigue, reaction time, sustained attention, time change

\section{Introduction}

Since the circadian rhythms of the activities of the body were identified, this question has always interested the scientists: how changes in these rhythms can affect the brain and body function? (Rusak \& Zucker, 1979). Since living in industrial societies has to be according to some rules and these rules are defined according to the needs of the society, the discussion about shifting work and its effects on people's lives has been one of the concerns of the governments (Rutenfranz et al., 1977). Perhaps the main issue in this regard is related to sleeplessness and its side effects on the workers of the companies who have to do shift work (Reid \& Abbott, 2015). The research in this regard has been expanded due to the invention of the jet airplanes and occurrence of a phenomenon called jet lag in passengers who have to travel by these airplanes for long duration's and their daily time is affected by long distance travel (Chapman et al., 2012). Several studies have shown that this phenomenon is caused by the activities of neurons, which are sensitive to light in the suprachiasmatic nucleus hypothalamus, which secret melatonin hormone when the coming light to eyes decreases and makes the activity cycle in these neurons get activated and eventually led to decrease or increase the body's activities (Ferrell \& Chiang, 2015). According to cellular-molecular mechanism studies have shown that among bipolar neurons, which are in charge of transferring messages from retina to brain, there are neurons that are stimulated by light and transfer their messages through retina-hypothalamus pathway to the suprachiasmatic nucleus of the hypothalamus. In this 
nucleus these neurons secret vasoactive intestinal peptide on the glands and stimulate the neurons of this nucleus which release melatonin into the hypothalamus pituitary portal vein. For this reason, if for any reason the light-dark cycle is disturbed by changing the amount of light which gets into the eyes, it will eventually led to changes in the activity of suprachiasmatic nucleus and changes in the secretion of melatonin. Besides that, these changes will lead to changes in circadian rhythm activities of neuron systems and glands and this in return will cause stress in people (Lucas et al., 2012). This stress is considered as a chronic stress in people who have to travel long distances with ultra sound airplanes or the people who have to do shift work and it may led to different changes in the brain activity (Mate et al., 2014). Various studies have shown that chronic stress stimulates the hypothalamus-pituitary- adrenal axis (HPA) and increase the cortisol concentration in the blood continuously and chronically (Asalgoo et al., 2015; Bahari et al., 2015; McEwen et al., 1999; Salehi et al., 2015). This led to stimulation of cortisol receptors in some parts of the brain, where there is a large number of cortisol receptors (McEwen et al., 2013). This continuous stimulation activates the brain's glutamate system and this system will stimulate N-Methyl-D-Aspartate (NMDA) receptors and cause excessive entrance of calcium ions into the cells (Lupien \& Lepage, 2001; Bahari et al., 2014). The increases in the entrance of calcium ions in a short period by stimulation of different channels duplicate of different genes and increase the activity of kinase enzymes (Eslamizade et al., 2015; Lupien \& Lepage, 2001). These activities will show themselves in the form of Long-Term-Potentiation (LTP) or other forms of synapsis forming and increase in the number and volume of dendritic spines in the target tissues. Furthermore, when the stimulation time increases and calcium ions enter into the cells excessively through NMDA, the activity of the enzymes, which mostly have a role in apoptosis becomes functional and led to the destruction of cytoskeleton, decrease in the number and size of the dendritic spines and decrease in the volume and number of synapses (Lupien \& Lepage, 2001). Studies have shown that hippocampus as an important brain structure has a role in memory (Ferrell \& Chiang, 2015; Lupien \& Lepage, 2001; Meftahi et al., 2014; Meftahi et al., 2015). Stress in the short time, by quickly increasing cortisol concentration, increases cognitive abilities such as memory. But, studies have indicated that memory's capability is decreased when exposed to chronic stress (Lupien, 2005). Thus, it seems that the chronic stress, not only decreases the memory, but also it will cause problems in mental processes related to the memory, such as decision making, responding, the ability to integrate different sensory inputs and different kinds of memory (Wolkowitz et al., 2004; Ghodrat et al., 2014; Husseini et al., 2016).

The paced auditory serial addition test (PASAT) is one of the most often used tests by neuropsychologists, for the evaluation of awareness processing of patients. This test is one of the tools to evaluate the role of short-term memory and attention in which the stimulant is provided through vision or hearing. PASAT test was used for the first time by Sampson and Gronwall (Tombaugh et al., 2006). They believed that this test measures the speed of information processing. However, nowadays this test is used to measure multiple functional areas of the brain because carrying out this test includes the complete and the successful function of cognitive functions especially the ones which are related to attention and awareness. Also, PASAT test has illustrated good psychometric features such as a high-level of inner compatibility and test validity-test-retest (Tombaugh et al., 2006). PASAT test is designed to evaluate the effects of brain damages on the cognitive function of the brain in the patients with a wide range of neural-psychological disorders such as multiple sclerosis (MS), brain damages caused by accident, chronic tiredness syndrome, tuberculosis, hypoglycemia and depression (Vollmer et al., 2015). Since, in this study time change has been considered as a stress pattern which in the long time can disturb the intellectual capacity, through the application of PASAT test, changes in cognitive function such as attention, mental tiredness, and general health are investigated in the individuals who volunteered for the study, before and after changes in working hours in Tehran city. Also, cortisol salivary concentration was investigated in these individuals as the most important stress hormone (W. E. Bunney \& B. G. Bunneym, 2000).

\section{Materials and Method}

\subsection{Subjects}

Eleven male individuals with the age range of 21-23 years volunteered and took part in the study after they were examined by a psychiatrist and a neurologist. None of the participants had any background problems with their hearing, vision and speaking, they did not use any sort of special medicine (apart from acetaminophen and other common sedatives) and they were non-smokers. They were also tested for their hearing ability. The average weight of these individuals was $75 \pm 0 / 8 \mathrm{~kg}$ and their average height was $172 \pm 5 \mathrm{~cm}$. Their level of education was a diploma. Apart from a change in working hours, there were not any other disturbing factors. All of the participants had the advantage of free insurance in experimental days. Their nutrition was also similar. 


\subsection{Experimental Procedures}

After training these individuals on the 27th of February, 2014 at 1-3 pm (before the time changes to spring time, one hour; which occur annually) they were tested by PASAT. On the 27th of April, 2014 they were again tested at 1-3 pm (after the time changes to spring time). From all the individual saliva samples were taken to measure the amount of salivary cortisol (Reid \& Abbott, 2015).

PASAT which was carried out in this experiment was as follows: In this experiment 61 numbers from one to nine were presented to the participants randomly with the time gap of three seconds. The participants had to add up the two last consecutive numbers and give the total (of the two numbers) before the new numbers were presented. During each experimental part participants would give some correct responses and these correct responses (the accuracy of responses) for each range would be compared before and after the time changes (Tombaugh, 2006). Also, the average of responding time (the speed of responding), the longest range of correct responses (continuous attention) and the longest range of wrong responses (mental fatigue) were tested in this experiment (Tombaugh, 2006). To evaluate salivary cortisol, cortisol ELISA KIT, (Diagnostics Biochem Canada Inc.) was used. Sample saliva from the participants were collected in falcon tubes with the capacity of $10 \mathrm{ml}$ and stored in the freezer under- 20 centigrade before the PASAT started. On the day of the experiment first the samples were melted in the normal room temperature and after centrifuging with the rotation of 3000 for five minutes, 20 microliter of each sample was separated for the test.

\subsection{Data Analysis}

The data are indicated by average standard deviation (Mean+SEM). The Paired-test was used to identify significant between-group. A value of $\mathrm{P}<0.05$ was considered as significant.

\section{Results}

\subsection{The Effects of Time Change in Salivary Cortisol Concentration}

In this part of the study, the amounts of cortisol in the collected saliva samples were measured by applying the ELISA method. The results showed that the amount of plasma saliva before and after the time changes had a meaningful difference $\left(t_{10}=2.24, P<0.01\right)$ Figure 1 . Pearson correlation test revealed that the $\mathrm{r}^{2}$ for before the time changes was 0.83 and for after time change was 0.698 .

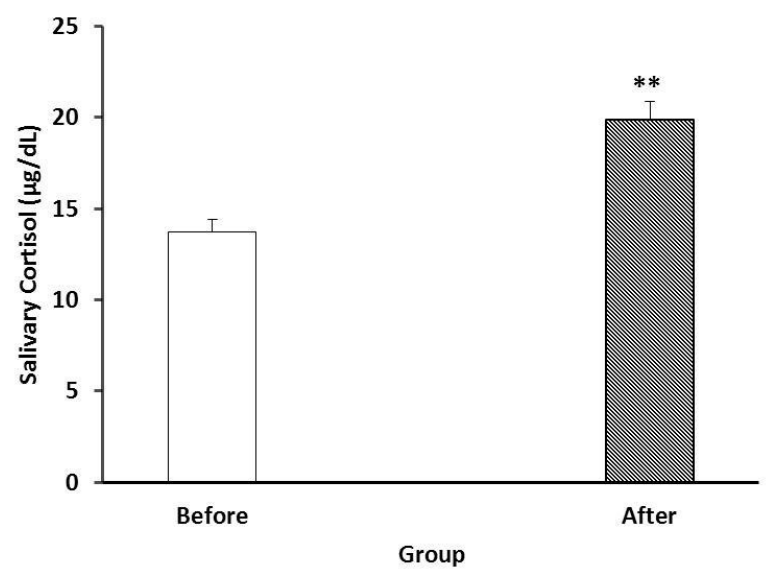

Figure 1. Salivary cortisol concentration in volunteers before and after time change. As it is illustrated, time changes increased cortisol salivary concentration

Source: Data is shown as mean $\pm \mathrm{SEM}$ of salivary cortisol, $* * * \mathrm{P}<0.001$ different between the groups.

\subsection{The Effects of Time Change in General Mental Health}

The result of general mental health before and after time change is shown in Figure 2. The general mental health (the number of correct responses) was significantly higher before the time changes than after the time changes, $\left(\mathrm{t}_{10}=1.78, \mathrm{P}<0.01\right.$, Figure 2). Pearson correlation test revealed that the $\mathrm{r}^{2}$ for before the time changes was 0.83 and for after time change was 0.698 . 


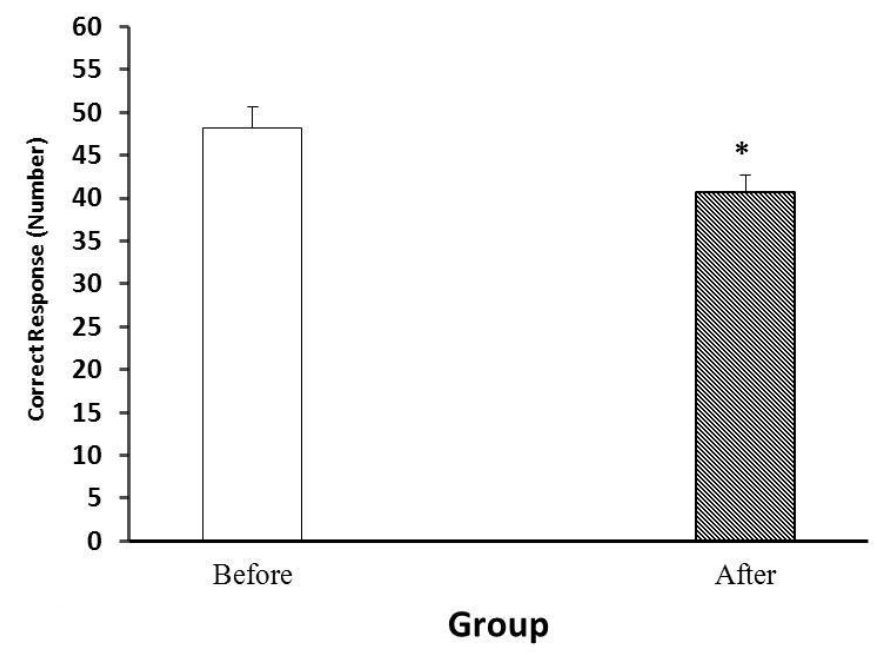

Figure 2. General mental health differences in volunteers before and after time change. General mental health (the number of correct responses) in volunteers before the time changes was significantly higher than that after the time changes

Source: Data is shown as mean $\pm \mathrm{SEM}$ of global mental health, ${ }^{*} \mathrm{P}<0.05$ different between the groups.

\subsection{The Effects of Time Change on Reaction Time}

The results gained from PASAT indicated that the speed of responding in individuals after the time changes in comparison to before the time changes decreased, but this difference is not meaningful from a statistical point of view. $\left(\mathrm{t}_{10}=0.80, \mathrm{P}<0.01\right.$, Figure 3). Pearson correlation test revealed that the $\mathrm{r}^{2}$ for before the time changes was 0.901 and for after time change was 0.71 .

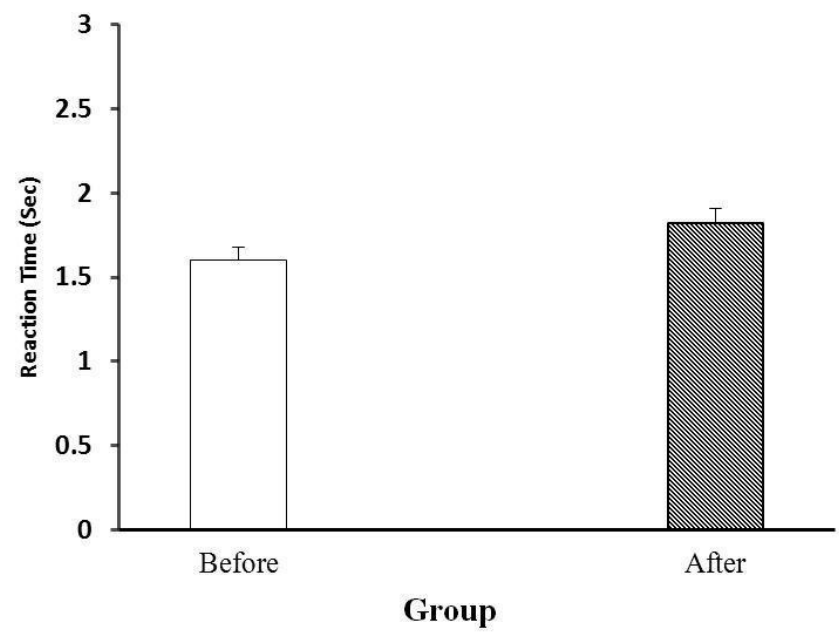

Figure 3. Reaction time changes before and after time change in the volunteers. Reaction time was not statistically significant different before and after the time changes

Source: Data is shown as mean $\pm \mathrm{SEM}$ of reaction time; there was no significant difference between the groups.

\subsection{The Effects of Time Change on Sustained Attention}

As it was mentioned before, in PASAT the longest correct response serial was considered as a criterion for continuous attention. The results showed that continuous attention in participants after time change decreased considerably in comparison before the time changes (working hours), $\left(\mathrm{t}_{10}=2.07, \mathrm{P}<0.05\right.$, Figure 4). Pearson correlation test revealed that the $r^{2}$ for before the time changes was 0.86 and for after time change was 0.801 . 


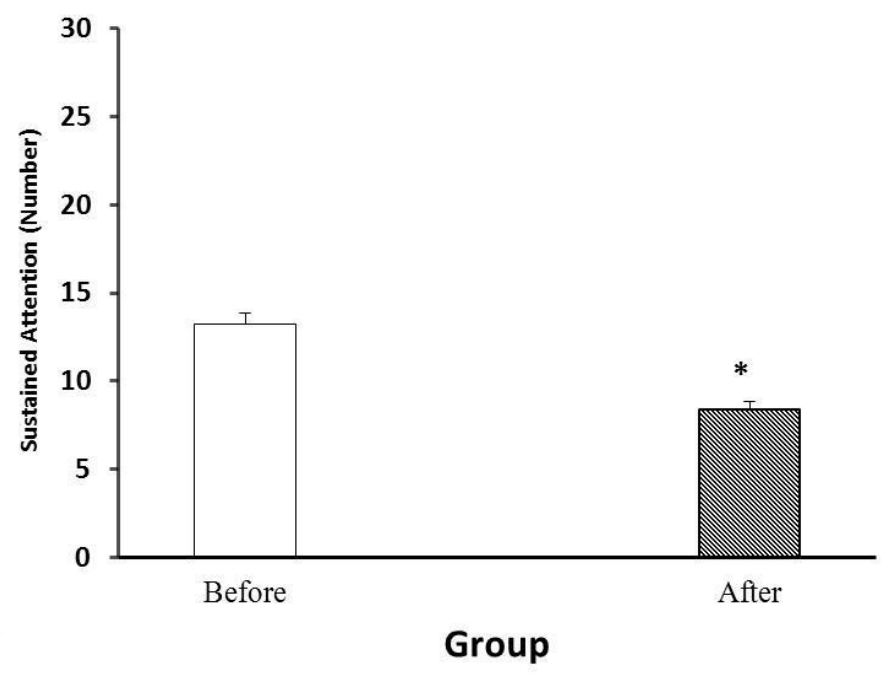

Figure 4. Change in sustained attention in the volunteers before and after time change. Sustained attention was significantly higher before than that of after the time changes

Source: Data is shown as mean $\pm \mathrm{SEM}$ of sustained attention, ${ }^{*} \mathrm{P}<0.05$ different between the groups.

\subsection{The Effects of Time Change on Mental Fatigue}

In PASAT the longest wrong response serial was considered as a criterion for mental tiredness. The results indicated that the individuals after time change had more mental fatigue, $\left(\mathrm{t}_{0}=2.976, \mathrm{P}<0.01\right.$, Figure 5). Pearson correlation test revealed that the $\mathrm{r}^{2}$ for before the time changes was 0.95 and for after time change was 0.73 .

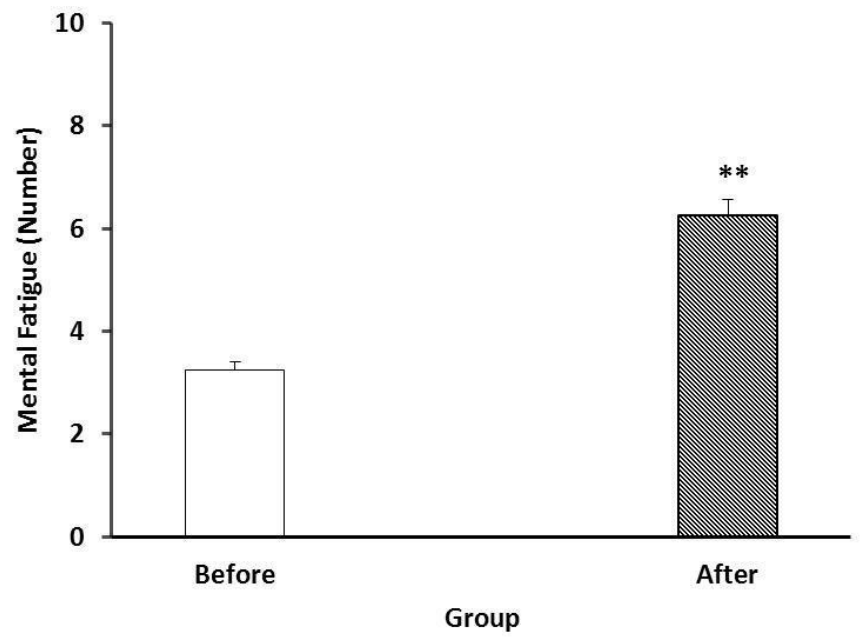

Figure 5. Mental fatigue comparison before and after time change in the volunteers. Mental fatigue was significantly lower before the time changes compared to the after the time changes

Source: Data is shown as mean $\pm \mathrm{SEM}$ of mental fatigue. ${ }^{* *} \mathrm{P}<0.01$ different between the groups.

\section{Discussion}

The effects of the time change on biological indicators in human beings are known. The studies in this area indicate that time change can cause the disturbance of the balance between genes, proteins, the activity of endocrine glands and eventually brain's cognitive activities such as memory and learning (Mate et al., 2014; W. E. Bunney \& B. G. Bunneym, 2000; Wyatt et al., 1999). For different reasons such as economical motives and others, changes in working hours are carried out by many countries (Rutenfranz et al., 1977). 
Our study is done by applying PASAT test, which is fairly efficient software for the analysis of cognitive function of the brain. In this study, the volunteers were low $(n=11)$, and it may be questioned that the results would change if the sample size became greater, but the parameters in which were measured in the present study were quantitative and therefore, the effect of small sample size would be diminished. Also, PASAT software methods and ELISA method which was used in this study were sensitive enough to identify minor differences in the experiments. It showed that the general cognitive functions of the brain after time change decrease and this decrease is in accordance with the increase of cortisol salivary concentration of the participants. Chronic stress-a kind of stress, which happening more than once or is suggested for a long time (McEwen \& Morrison, 2013) or after repetitive injection of glucocorticoid- decreases the cognitive skills such as verbal memory (Lupien \& Lepage, 2001). This reduction is related to the direct effect of glucocorticoid on the reduction of the number and volume of dendritic spines in special sections of the brain such as hippocampus. Plasma concentration of glucocorticoid after chronic stress increases and this reduces the volume of the brain, especially in the hippocampus (McEwen \& Morrison, 2013). This is indicated as a reason for reduction of memory in animals and human beings which for a long time are exposed to chronic stress. Although in this study the different kinds of memory are not analyzed, but probably the memories of the participants following the increase of salivary cortisol have been disturbed. It may be argued that the salivary cortisol concentration could increase following other kinds of stress and cannot be directly related to the time change factor. We can say that many studies have been carried out which show that time change increases stress hormones for a long time in individuals. Also, changes in working hours in workers of the factories which apply shift work policy can cause an increase in plasma cortisol and for this reason changing shifts and changing sleeping time is considered a stress factor (Rutenfranz et al., 1977).

In this study general mental health of the participants before changing working hours were better than after it was changed. It seems that changes in working hours, affects the general mental health and can be harmful for cognitive functions. General mental health is one of the most important signs of correct mental function. It shows that there is a connection between the different parts of the nervous system related to cognitive functions such as memory, learning and fluent verbal abilities (McEwen \& Morrison, 2013). Since these connections in the nervous system are designed for coordinated operations in a process and are reasonably vital, any factor which can disturb this connection and reduces its efficiency can affect the output (in this study the output was the number of correct answers). Stress hormones such as cortisol, damage these connections and reduce the function of brain such as memory, learning and judgment (Miller, 2000). Considering the increase of salivary cortisol concentration in the individuals after time change-which means an increase in plasma concentration- the reduction in the efficiency of mental performance in individuals after time change, is understandable.

In the next part of the study the speed of answering the questions were not meaningfully different before and after the time changes. Even though there was a relative decrease in answering after the time changes. It has to be said that the speed of answering is directly related to verbal skills and if an individual has acquired these skills, changing them with chronic stress is not so easy. This is because verbal skills have been developed gradually and to some extent are independent of stress conditions of an individual and therefore they are less affected by environmental factors (Maheu et al., 2005). In this study the participants showed more focused attention before than after the time changes, which means that a change in working hours can lead to reduce the capability of the brain in pursuing a target.

The amount of mental tiredness in the participants before the time changes was much less than when the working hours changed. Mental tiredness is measured by counting the number of wrong answers (Tombaugh, 2006). An increase in the number of wrong answers means that the brain has not been able to focus enough and produce accurate and acceptable answers (Tombaugh, 2006). Circadian disturbance can contribute to cognitive damages. For instance, a mouse model of circadian interruption shows cognitive inflexibility and shrinkage of dendrites in the prefrontal cortex (McEwen \& Morrison, 2013). Moreover, it was shown that short-recovery crews had impaired performance in a psychomotor task, reacting more slowly and with more errors when compared to a long-recovery crew (Karatsoreos et al., 2011).

It is well known that stress, damage frontal and hippocampal functions through the release of cortisol and influence on attention processing. Sänger et al., (2014) showed that stress impairs the intention-based attentional allocation and leading to a strong distractibility during attentional information selection (Sänger et al., 2014). Thus, changes in working hours could induce stress system function and increasing the cortisol may reduce neuronal function and decrease attention processing. In the previous studies it has been recognized that stress reduced decision making ability in animals and human and could disturb different kinds of memory (Lupien et al., 2005; Miller, 2000). Since the scores gained by the participants before the time changes have been better than 
the scores they gained after the time changes, it seems that the time change has had negative effects (at least) on the performance of the brain.

\section{Conclusion}

In conclusion, this study by applying an accurate and fairly simple cognitive test and by using an important hormone criterion to stress showed that changes in working hours can act as a stress stimulus and at least it can disturb part of brain's cognitive function. An action which at first may seem unimportant, but if this phenomenon happens to millions of people who are under time change influence, it will not present a desirable vision.

\section{Acknowledgments}

This work was conducted as a part of the student thesis in Neuroscience Research Center, Baqiyatallah University of Medical Sciences, Tehran, Iran and supported by a grant from the Neuroscience Research Center, Baqiyatallah University of Medical Sciences, Tehran, Iran.

\section{Competing Interests Statement}

The authors declare that there is no conflict of interests regarding the publication of this paper.

\section{References}

Asalgoo, S., Jahromi, G. P., Meftahi, G. H., \& Sahraei, H. (2015). Posttraumatic Stress Disorder (PTSD): Mechanisms and Possible Treatments. Neurophysiology, 47(6), 482-489. http://dx.doi.org/10.1007/ s11062-016-9559-9

Bahari, Z., Manaheji, H., Dargahi, L., Daniali, S., Norozian, M., Meftahi, G. H., \& Sadeghi, M. (2015). Time profile of nNOS expression in the spinal dorsal horn after L5 spinal root transection in rats. Neurophysiology, 47(4), 287-94. http://dx.doi.org/10.1007/s11062-015-9535-9

Bahari, Z., Manaheji, H., Hosseinmardi, N., Meftahi, G. H., Sadeghi, M., Danialy, S., \& Noorbakhsh, S. M. (2014). Induction of spinal long-term synaptic potentiation is sensitive to inhibition of neuronal NOS in 15 spinal nerve-transected rats. EXCLI, 13, 751-760.

Bunney, W. E., \& Bunneym B. G. (2000). Molecular clock genes in man and lower animals: Possible implications for circadian abnormalities in depression. Neuropsychopharmacology, 22(4), 335-45. http://dx.doi.org/10.1016/S0893-133X(99)00145-1

Chapman, D. W., Bullock, N., Ross, A., Rosemond, D., \& Martin, D. T. (2012). Detrimental effects of west to east transmeridian flight on jump performance. Eur J Appl Physiol, 112(5), 1663-9. http://dx.doi.org/ 10.1007/s 00421-011-2134-6

Eslamizade, M. J., Saffarzadeh, F., Mousavi, S. M. M., Meftahi, G. H., Hosseinmardi, N., Mehdizadeh M., \& Janahmadi, M. (2015). Alterations in CA1 pyramidal neuronal intrinsic excitability mediated by th channel currents in a rat model of amyloid beta pathology. Neuroscience, 305, 279-292. http://dx.doi.org/10.1016/j. neuro science.2015.07.087

Ferrell, J. M., \& Chiang, J. Y. (2015). Circadian rhythms in liver metabolism and disease. Acta Pharm Sin B, 5(2), 113-22. http://dx.doi.org/10.1016/j.apsb.2015.01.003

Ghodrat, M., Sahraei, H., Razjouyan, J., \& Meftahi, G. H. (2014). Effects of a Saffron Alcoholic Extract on Visual Short-Term Memory in Humans: A Psychophysical Study. Neurophysiology, 46(3), 247-253. http://dx.doi.org/10.1007/s11062-014-9436-3

Husseini, Y., Sahraei, H., Meftahi, G. H., Dargahian, M., Mohammadi, A., Hatef, B., ... Behzadnia, M. (2016). Analgesic and anti-inflammatory activities of hydro-alcoholic extract of Lavandula officinalis in mice: Possible involvement of the cyclooxygenase type 1 and 2 enzymes. Revista Brasileira de Farmacognosia, 26(1), 102-108. http://dx.doi.org/10.1016/j.bjp.2015.10.003

Karatsoreos, I. N., Bhagat, S., Bloss, E. B., Morrison, J. H., \& McEwen, B. S. (2011). Disruption of circadian clocks has ramifications for metabolism, brain, and behavior. Proc Natl Acad Sci USA, 108, 1657-1662. http://dx.doi.org/10.1073/pnas.1018375108

Lucas, R. J., Lall, G. S., Allen, A. E., \& Brown, T. M. (2012). How rod, cone, and melanopsin photoreceptors come together to enlighten the mammalian circadian clock. Prog Brain Res, 199, 1-18. http://dx.doi.org/10. 1016/B978-0-444-59427-3.00001-0

Lupien, S. J., \& Lepage M. (2001). Stress, memory, and the hippocampus: Can't live with it, can't live without it. Behav Brain Res, 127(1-2), 137-58. http://dx.doi.org/10.1016/S0166-4328(01)00361-8 
Lupien, S. J., Fiocco, A., Wan, N., Maheu, F., Lord, C., Schramek, T., \& Tu, M. T. (2005). Stress hormones and human memory function across the lifespan. Psychoneuroendocrinology, 30(3), 225-42. http://dx.doi.org/10. 1016/j.psyneuen.2004.08.003

Maheu, F. S., Joober, R., \& Lupien, S. J. (2005). Declarative memory after stress in humans: Differential involvement of the beta-adrenergic and corticosteroid systems. J Clin Endocrinol Metab, 90(3), 1697-704. http://dx.doi.org/10.1210/jc.2004-0009

Mate, I., Madrid, J. A., \& De la Fuente, M. (2014). Chronobiology of the neuroimmunoendocrine system and aging. Curr Pharm Des, 20(29), 4642-55. http://dx.doi.org/10.2174/1381612820666140130201131

McEwen, B. S., \& Morrison, J. H. (2013). The brain on stress: Vulnerability and plasticity of the prefrontal cortex over the life course. Neuron, 79, 16-29. http://dx.doi.org/10.1016/j.neuron.2013.06.028

McEwen, B. S., de Leon, M. J., Lupien, S. J., \& Meaney, M. J. (1999). Corticosteroids, the aging brain and cognition. Trends Endocrinol Metab, 10, 92-96. http://dx.doi.org/10.1016/S1043-2760(98)00122-2

Meftahi, G., Ghotbedin, Z., Eslamizade, M. J., Hosseinmardi, N., \& Janahmadi, M. (2015). Suppressive Effects of Resveratrol Treatment on the Intrinsic Evoked Excitability of CA1 Pyramidal Neurons. Cell Journal (Yakhteh), 17(3), 532.

Meftahi, G., Janahmadi, M., \& Eslamizade, M. J. (2014). Effects of resveratrol on intrinsic neuronal properties of CA1 pyramidal neurons in rat hippocampal slices. Physiology and Pharmacology, 18(2), 144-155. Retrieved from http://www.phypha.ir/ppj/browse.php?a_code=A-10-25-112\&slc_lang=en\&sid=1

Miller, E. K. (2000). The prefrontal cortex and cognitive control. Nature Reviews Neuroscience, 1, 59-65. http://dx.doi.org/10.1038/35036228

Reid, K. J., \& Abbott, S. M. (2015). Jet Lag and Shift Work Disorder. Sleep Med Clin, 10(4), 523-35. http://dx.doi.org/10.1016/j.jsmc.2015.08.006

Rusak, B., \& Zucker, I. (1979). Neural regulation of circadian rhythms. Physiol. Rev., 59(3), 449-526.

Rutenfranz, J., Colquhoun, W. P., Knauth, P., \& Ghata, J. N. (1977). Biomedical and psychosocial aspects of shift work: A review. Scand J Work Environ Health, 3165-82. http://dx.doi.org/10.5271/sjweh.2777

Salehi, M., Eimani, H., Sahraei, H., \& Meftahi, G. H. (2015). Stress Can Changes Reward System Function in Second-Generation (F2): A Review. Advances in Bioresearch, 6(5), 4-14.

Sänger, J., Bechtold, L., Schoofs, D., Blaszkewicz, M., \& Wascher, E. (2014). The influence of acute stress on attention mechanisms and its electrophysiological correlates. Frontiers in behavioral neuroscience, 8(353), $1-13$.

Tombaugh, T. N. (2006). A comprehensive review of the Paced Auditory Serial Addition Test (PASAT). Arch Clin Neuropsychol, 21(1), 53-76. http://dx.doi.org/10.1016/j.acn.2005.07.006

Vollmer, T., Huynh, L., Kelley, C., Galebach, P., Signorovitch, J., DiBernardo, A., \& Sasane, R. (2015). Relationship between brain volume loss and cognitive outcomes among patients with multiple sclerosis: A systematic literature review. Neurol Sci, 4, 1-15.

Wolkowitz, O. M., Lupien, S. J., Bigler, E., Levin, R. B., \& Canick, J. (2004). The "steroid dementia syndrome": An unrecognized complication of glucocorticoid treatment. Ann N Y Acad Sci, 1032, 191-4. http://dx.doi. org/10. 1196/annals.1314.018

Wyatt, J. K., Ritz-De Cecco, A., Czeisler, C. A., \& Dijk, D. J. (1999). Circadian temperature and melatonin rhythms, sleep, and neurobehavioral function in humans living on a 20-h day. Am J Physiol, 277(4), $1152-63$.

\section{Copyrights}

Copyright for this article is retained by the author(s), with first publication rights granted to the journal.

This is an open-access article distributed under the terms and conditions of the Creative Commons Attribution license (http://creativecommons.org/licenses/by/3.0/). 